\title{
The potential of synthetic biology: a view from the European Academies Science Advisory Council
}

\author{
Robin Fears and Volker ter Meulen
}

As mentioned in a recent Editorial

(Supporting the synthetic revolution. Nature Rev. Microbiol. 9, 2 (2011)) ${ }^{1}$, the emerging recommendations from the US Presidential Commission for the Study of Bioethical Issues mark a new phase in developing coordination and public communication in synthetic biology in the United States. Similar strategic issues are also receiving increasing attention in Europe, for example in the European Parliament ${ }^{2}$.

At the end of 2010, the European Academies Science Advisory Council (EASAC) published a report ${ }^{3}$ reviewing research progress and the concomitant need for international debate on regulatory issues. EASAC was formed by the national science academies of the European Union member states to enable them to collaborate in providing advice to European policy-makers; outputs aim to deliver evidence-based advice that is comprehensible, relevant and timely. Our latest report explores what contribution synthetic biology might make to tackling societal objectives, what scientific and technological challenges must be overcome and what else might prevent the field from realizing its potential.

In Europe, as elsewhere, among the issues under intense scrutiny is whether synthetic biology will prove to be a truly transformational technology or, less radically, will represent an incremental advance. Should dedicated policy be introduced to advance synthetic biology, or would this risk creating additional obstacles by making unnecessary distinctions from other fields? There are significant governance implications for biosafety (protecting legitimate users) and biosecurity (protecting against intentional misuse). The scientific community has a responsibility to help policy-makers with issues for risk assessment and with managing uncertainty occasioned by the changing boundaries of synthetic biology, so as to find the right balance between scientific self-governance and statutory regulation. To those who contemplate new options for regulation, EASAC affirms that it is vital to prevent inadvertent negative impacts on research.

The EASAC report explores research and innovation strengths in Europe and the public funding agenda. Admittedly, it can be difficult to unambiguously differentiate some of the opportunities manifested in synthetic biology from recombinant DNA technology in general. But whatever the uncertainties about particular applications, synthetic biology research will also improve our understanding of natural biological systems - because synthetic systems can be simplified to allow for experiments that would be difficult to interpret if carried out in their full natural context. Research funders have a responsibility to support the underpinning scientific disciplines, develop integrative multidisciplinary initiatives, promote translational research and prepare the next generation of skilled researchers.
Academies stand ready to play their part in advising policy-makers and encouraging and informing public debate based on accurate evidence about current progress and future possibilities. As the Editorial noted, judging from surveys in the United Kingdom, there is measurable public support for synthetic biology, but the danger remains that sensationalist accounts of research by the press can exacerbate public concerns. A recent European Commission study of public attitudes across Europe ${ }^{4}$ found that although synthetic biology is considered a sensitive technology, more than half the respondents agreed that it should be governed according to the evidence relating to risks and benefits, not according to moral concerns. The academies, together with others in the scientific community, have an important role in developing an environment in which the public can realistically assess the alarmist assertions appearing in media reports.

Robin Fears and Volker ter Meulen are at the European Academies Science Advisory Council, German Academy of Sciences Leopoldina,

Postfach 110543, D-06019 Halle (Saale), Germany.

e-mails: robin.fears@easac.eu; termeulen@vim.uni-wuerzburg.de doi:10.1038/nrmicro2498-c1

1. No authors listed. Supporting the synthetic revolution. Nature Rev. Microbiol. 9, 2 (2011).

2. Science and Technology Options Assessment Group Making perfect life: bio-engineering in the $21 \mathrm{st}$ century. Science and Technology Options Assessment [online] http://www.europarl.europa.eu/stoa/events/ workshop/20101110/default_en.htm (2010).

3. EASAC. Realising European potential in synthetic biology: scientific opportunities and good governance. EASAC [online] http://www.easac.eu/home/reports-andstatements/detail-view/article//synthetic-bi.html (2010)

4. European Commission. Europeans and Biotechnology in 2010. Winds of Change? Europa [online] http:// bookshop.europa.eu/is-bin/INTERSHOP.enfinity/WFS/ EU-Bookshop-Site/en_GB/-/EUR/ViewPublicationStart?PublicationKey = KINA24537 (2010).

\section{Acknowledgements}

As Chairman (V.t.M.) and secretary (R.F.) of the EASAC Working Group, we thank the other members: B. Friedrich (Germany), A. Kraszewski (Poland), U. Landegren (Sweden), P. Leadlay (UK), G. Marino (Italy), V. Paces (Czech Republic), B. Poolman (the Netherlands), G. Posfai (Hungary), R. Thauer (Germany), G. Thireos (Greece) and J. Weissenbach (France). Competing interests statement

The authors declare no competing financial interests 